\title{
An empirical study on the effect of speech therapy with cognitive behavior therapy on reducing the severity of stuttering and anxiety
}

\author{
Pegah Ansari ${ }^{a^{*}}$, Yousef Gorji ${ }^{b}$ and Bijan Shafie ${ }^{c}$
}

${ }^{a}$ Ms Student, Counseling Department, Islamic Azad University of Khomeinishahr, Khomeinishahr Branch, Daneshju Blvd, Iran

${ }^{b}$ Assistant professor, Counseling Department, Islamic Azad University of Khomeinishahr, Khomeinishahr Branch, Daneshju Blvd, Iran.

${ }^{c}$ Assistant professor, Speech Therapy Department, School of rehabilitation sciences, Isfahan University of Medical Sciences, Isfahan, Iran

\section{H R O N I C L E}

Article history:

Received August 16,2013

Received in revised format

12 September 2013

Accepted 1 November 2013

Available online

November 12013

Keywords:

Speech therapy

Cognitive behavior

Therapy

Stuttering

Anxiety

Adults

\section{A B S T R A C T}

\begin{abstract}
The purpose of this research is to investigate the impact of speech therapy with Cognitive Behavior Therapy (CBT) on reducing the severity of stuttering \& anxiety for adults who stutter in the city of Isfahan, Iran. The study used a semi-experimental design with pre-test/post-test control groups and it was conducted among 24 clients. The sample was selected through available sampling method among the clients suffering from stuttering and attended public speech therapy clinics of Isfahan. The measurement instruments were Stuttering Severity Instrument (SSI4) and Beck's Anxiety Inventory (BAI). After doing the pretest, clients were placed into one experimental group of speech therapy with CBT and one control group. Speech therapy for this research included ten 45-minutes sessions accomplished for each individual subject and CBT included ten 90-minutes group sessions. After finishing the therapy sessions, the posttest was executed on both groups. For statistical analysis of data, Analysis of Covariance was carried out. The research findings indicated that speech therapy with CBT reduced the severity of Stuttering and Anxiety. Speech therapy with CBT is effective in reducing Stuttering \& Anxiety.
\end{abstract}

\section{Introduction}

Stuttering is a relatively common speech fluency disorder detected frequently in the society and anxiety is one of the most psychological conditions observed along stuttering. Stuttering happens when the flow of speech is interrupted abnormally by repetition, prolongation and interjection of words, sounds as well as syllables, even phrases, and blocking of the mouth. It is sometimes accompanied by dependent behaviors (Guitar, 2006). Anxiety is one of the main elements of stuttering (Holit, 1985). Those who stutter appear to experience higher than normal levels of anxiety, independent of speech (Craig et al, 2003).

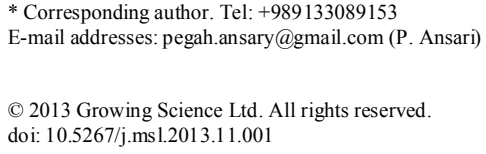


There are different methods recommended for treating stuttering, including speech therapies which are performed by speech \& language pathologists, and also therapies conducted by psychologists and counselors (Menzies et al., 2006). Enhancing fluency of speech is one of the techniques employed in stuttering therapies, which includes methods such as prolongation, airflow, pause and pauseprolongation. In these methods, the primary objective is to reduce speech speed and create necessary changes in suprasegmental features of speech that causes increase of coordination in speech performance. One of the methods employed by counselors and psychologists in treating anxiety is cognitive-behavior therapy. Specialists of this approach believe that the purpose of this type of therapy is relieving symptoms, facilitating improvement of the disorder, assisting the individuals in resolving most pressuring problems, and teaching tools to prevent relapse of the disorder (Beck, 1995). This therapy includes diagnosis and evaluation methods for automatic thoughts, training cognitive errors, responding to automatic thoughts, positive self-talk, problem-solving, and ultimately graded exposure (Beck, 1995; Hawton et al. 2010; Free, 2004).

CBT focuses on biological-mental-social aspects of stuttering. Initial symptoms of stuttering include social, psychological, and behavioral symptoms. Individuals suffering from stuttering get affected by the environment and their own speech in both cognitive and behavioral patterns. This kind of therapy is effective in reducing symptoms of stuttering and anxiety and it improves personal attitude towards speech (Bloodstein et al., 2008). CBT is an active, directed, organized, and goal-oriented approach, which is based on cooperation between therapist and patient, focused on problem, reliant on question process and explored strategic, and concentrated on the ongoing problems of the patient (Hawton, 1989). CBT is effective in reducing the symptoms of stuttering and cognitive errors, improving selfconfidence, improving the life quality of adults who stutter (Reddy \& Sharma, 2010). Ezrati et al. (2007) investigated the effect of cognitive-behavior therapy in reducing stuttering and social phobia among persons who stutter and reported that CBT was effective in reducing anxiety and emotional reactions associated with stuttering, but it was ineffective in reducing stuttering itself. They concluded that CBT is an important part of the treatment for persons who stutter because it leads to considerable improvement in their daily performance and anxiety.

Amster and Klien (2008) did a research on eight adults aged 27 to 56 and reported that CBT was effective in reducing stuttering especially in public and while speaking on the phone. The treatment was also effective in improving their self-confidence during speech, accepting stuttering, and spontaneous speech. Menzies et al. (2008) performed an investigation on thirty-two adults with chronic stuttering to studying the effects of CBT on anxiety and stuttering. The results showed that the CBT treatment was associated with significant and sustained improvements in psychological functioning but did not improve fluency. Reddy and Sharma (2010) performed an investigation to studying the efficacy of CBT in reducing the symptoms of stuttering and dysfunctional cognitions and in enhancing assertiveness in five clients with stuttering. The results of individual analysis stated that cognitive behavior strategies could be effective in reducing severity of stuttering, reducing anxiety, reducing the dysfunctional attitude and in enhancing assertiveness and improving quality of life of clients with stuttering. There are some studies that indicate traditional therapies and methods like, prolongation, pause have reduced but temporary effects on stuttering, whereas CBT can be effective on both reducing stuttering, through altering the attitude of the individual towards stuttering, and anxiety using simultaneous cognitive and behavioral changes (Bothe, 2003).

One of the most convincing reasons that explain why treating anxiety in stutterers has vital importance is that anxiety disorders carry failure potential in speech reconstruction in short-term. Some adults who stutter still report considerable levels of anxiety after their speech therapy. Therefore, success of speech therapies depends on anxiety management before or simultaneously with speech therapy.

The organization of this paper is organized as follows. We first present details of our different tests we implement on patients in section 2 presents details of our computational results and finally 
concluding remarks are given in the last to summarize the contribution of this paper. The current study has been done after searching in scientific sites in the country and failure in finding similar researches and is probably amongst the first researches in Iran done on adults who stutter. The purpose of this study is to examine the effectiveness of a combination of speech therapy and CBT in reducing stuttering and anxiety in the said individuals.

\section{The proposed method}

This study was a Phase I trial of the novel treatment intervention. The proposed study of this paper performs a semi-experimental design with pre-test post-test control groups. The method for choosing samples was available sampling. Accordingly, initially 30 adults with stuttering who had referred to public speech therapy clinics were chosen as the sample group after interview and diagnosis. Later 3 members from the experiment group left, so the same number of members was omitted from the control group as well (each group consisted of 12 individuals). The average age of participants was 23.08 years old ranging from 19 to 30,16 of them were male and 8 of them were female. In the beginning, all participants consented to be parts of the research. After that, all participants were tested for stuttering severity using SSI4 test individually and under similar circumstances by one of speech and language pathologist colleagues with 5 years clinical experience. Then all participants filled the Beck anxiety inventory (BAI). Then the individuals who had the inclusion criteria were randomly divided into two experiment and control groups. The criteria for selecting participants were:

1) Aged over 18 years 2) Have the $8^{\text {th }}$ grade certification of Iran pre-university education system 3 ) Have the minimum score of 10 in the SSI4 4) Have the minimum score of 8 in anxiety in the BAI 5) They had chosen to seek therapy themselves 6) Have the ability of participating regularly in the treatment sessions 7) Have no mental retardation (according to their background information) 8) Do not use any psychiatric medication for the duration of the trial 9) At least six month has passed since their speech therapy and medicinal therapy ended (if they had any). SSI4 was used for gathering data and its reliability for the total score of the test was 93/4. This test was introduced by Riley in 2009. Some studies in Iran reached face and content validity of the questionnaire through the approval of 10 speech and language pathologists and 10 adults with stuttering. Its reliability was calculated using Cronbach's Alpha method and the total score for the test was calculated at 0.98 . The test's reliability was reached as 0.87 by the researcher using Pearson correlation.

Beck (1995) introduced the BAI as the Beck anxiety questionnaire. Some studies in examining psychometrics properties of this test in Iranian population reported validity coefficient of about 0.72 and Cronbach's Alpha of 0.92 (Fathi Ashtiani, 2011). CBT in this research included cognitive behavior group training that was performed using different methods like recognizing and evaluating automatic thoughts and responding to them, positive self-talk, problem solving and graded exposure. The duration of treatment was ten 90-minutes weekly sessions. Speech Therapy included ten 45minutes sessions with individual training of speech techniques like prolongation and pause methods that were done weekly. The structure of treatment sessions was done according to general cognitive therapy principles that included review of the previous week individuals' events, determination of session's agenda, getting feedback from patients about previous session, review of previous sessions' assignments, determining new assignment, conclusion and in the end feedback of each session was taken. After the end of the treatment sessions, post-test was performed on both groups. Then the data was statistically analyzed. In order to analyze data, Covariance analysis test was used according to semi-experimental research design with pre-test post-test.

\section{The results}

Variables of this research included CBT and Speech Therapy techniques as independent variables and severity of stuttering and anxiety as dependent variables. For analyzing of the results, covariance 
analysis was performed. In order to test the normality, we use Shapiro-Wilk test, which are summarized in Table 1 as follows,

\section{Table 1}

The results of Shapiro-Wilk test

\begin{tabular}{llll}
\hline Variables & Group & Statistic & P-Value \\
\hline \multirow{2}{*}{ Stuttering } & Pre-Test & 0.977 & 0.627 \\
& Post-Test & 0.972 & 0.376 \\
\hline \multirow{2}{*}{ Anxiety } & Pre-Test & 0.949 & 0.057 \\
& Post-Test & 0.953 & 0.126 \\
\hline
\end{tabular}

As we can observe, P-Value is not statistically significant and we can accept normality. In order to check the homogeneity of variances, Levine test was used.

Table 2

The results of the Levine Test

\begin{tabular}{lllll}
\hline Variables & df1 & df2 & F & P-Value \\
\hline Stuttering & 2 & 33 & 6.11 & 0.005 \\
Anxiety & 2 & 33 & 2.29 & 0.116 \\
\hline
\end{tabular}

As we can see, P-Value is not significant. Thus, the null hypothesis of equal variances for stuttering scores of two groups is rejected and it means group variances were not homogenous.

Hypothesis 1: Speech therapy with CBT is effective in reducing stuttering in individuals over 18.

\section{Table 3}

Comparison of pre-test and post-test stuttering average score in control group and experiment group

\begin{tabular}{llll}
\hline Test & Group & Mean & Standard dev. \\
\hline \multirow{2}{*}{ Experiment } & Pre-Test & 18.75 & 4.59 \\
& Post-Test & 14.33 & 5.51 \\
\hline \multirow{2}{*}{ Control } & Pre-Test & 21.33 & 2.83 \\
& Post-Test & 21.33 & 2.83 \\
\hline
\end{tabular}

Table 4

Covariance Analysis results of Group membership effect on decreasing of stuttering in two groups of experiment and control

\begin{tabular}{llllllc}
\hline Variables & df & Mean Square & F & P-Value & Eta-Square & Power of Statistics \\
\hline Pre-Test & 1 & 60.336 & 50.81 & 0.001 & 0.795 & 1 \\
Groups & 1 & 13.101 & 48.24 & 0.001 & 0.538 & 0.997 \\
\hline
\end{tabular}

Table 4 shows that there is a significant difference between residual mean scores of the two groups $(\mathrm{P}<0.05)$, hypothesis was approved. Eta- square was \%53. Thus, the severity of stuttering reduced with speech therapy along with CBT. As we can observe from the results of Table 4 and Fig. 1, the severity of stuttering among experiment group has been reduced after the treatment.

Table 5

The results of Mann -Whitney U test

\begin{tabular}{llll}
\hline Groups & Mean & Z & $\mathrm{p}$ \\
\hline Control & 17.33 & 3.21 & 0.001 \\
\hline
\end{tabular}

As regards that the groups variances were not homogeneous in addition Covariance test, Mann Whitney U test were also used. P-Value is significance. Thus, the difference between average rating groups and reducing stuttering was significant.

Hypothesis 2: Speech therapy along with CBT is effective in reducing of anxiety amongst individuals over 18. 
Table 6

Comparison of pre-test and post-test Anxiety average score in experiment and control groups

\begin{tabular}{llll}
\hline Test & Group & Mean & Standard dev. \\
\hline \multirow{2}{*}{ Experiment } & Pre-Test & 17.33 & 5.22 \\
& Post-Test & 12.16 & 3.56 \\
\hline \multirow{2}{*}{ Control } & Pre-Test & 18.66 & 2.34 \\
& Post-Test & 18.91 & 2.39 \\
\hline
\end{tabular}

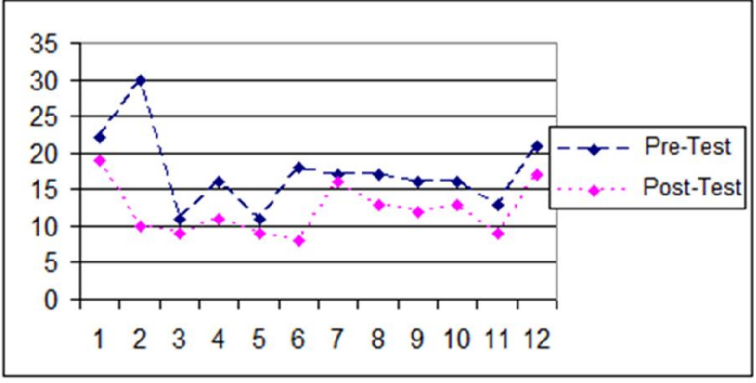

Fig.1. The results of SSI4

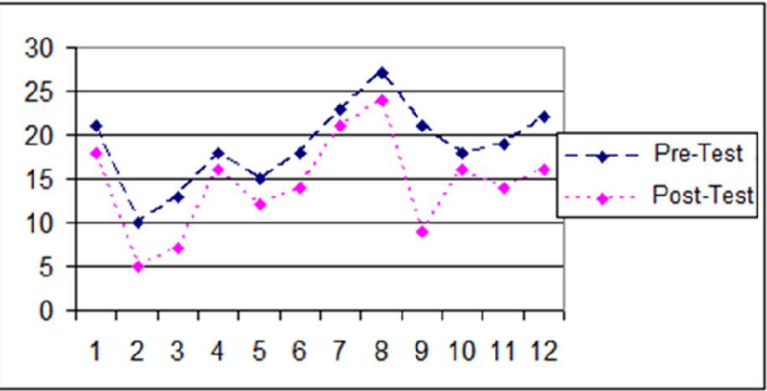

Fig. 2. The results of BAI

Table 7

Covariance Analysis results of group membership effect on reducing of anxiety in two groups of experiment and control

\begin{tabular}{lllllll}
\hline Variables & df & Mean Square & F & P-Value & Eta-Square & Power of Statistics \\
\hline Pre-Test & 1 & 46.05 & 6.17 & 0.021 & 0.227 & 0.659 \\
Groups & 1 & 22.40 & 3.77 & 0.001 & 0.594 & 1 \\
\hline
\end{tabular}

As it is shown in Table 7, there is a significant difference between average of the remaining score of anxiety in experiment and control groups. Therefore, the hypothesis is proved. Eta- square was $\% 59$. Hence, by using Speech Therapy along with CBT, anxiety was reduced. As we can observe from the results of Table 7 and Fig. 2, the severity of anxiety in experiment group have been reduced after the treatment.

\section{Discussion and conclusion}

The purpose of the current study was to examine the effect of speech therapy along with cognitivebehavioral therapy on reducing the severity of stuttering and anxiety in adults with stuttering. The statistical results of this research show that speech therapy methods along with CBT could be effective on reducing the severity of stuttering and anxiety. The results of this study are the same as previous researches (Amster \& Klein, 2008; Dilollo et al., 2007; Menzies et al., 2008; Reddy \& Sharma, 2010).

In explaining the effect of speech therapy along with CBT on reducing stuttering, it could be stated that according to reported therapeutical studies, methods for speaking more fluently like prolongation, pause, pause-prolongation are often methods that cause decrease in stuttering by reducing the speed of speech and make changes in characteristics of natural speech. These methods decrease stuttering by distracting individuals from their normal and usual speaking method, decreasing speed of speech and making necessary changes in suprasegmental characteristics of speech that increases coordination in speech and creating new speech pattern (Blood, 1995; Shafie \& Mehralian, 2003). CBT helps individuals recognize and modify their illogical thoughts through recognition of dysfunctional thoughts, training cognitive errors (most of dysfunctional thoughts mentioned by group members included cognitive errors like mental filter, exaggerated generalization and disqualifying the positive), evaluating these thoughts and responding to them. They also learn to pay more attention to their positive actions and experiences through positive self-expression and through the problem solving techniques they learn to choose suitable solution for their problems and 
eventually with graded exposure, they learn how to face difficult circumstances. The ultimate purpose of this treatment is to help individuals become self-therapist for solving their current and future problems and reach independency.

In summary, this research studied the impact of Speech Therapy along with CBT on reducing of stuttering and anxiety severity among adults with stuttering in the city of Isfahan. The results showed this combination of therapies positively affect reduce of severity of anxiety and stuttering. This result is an emphasis on performing CBT in treating stuttering which has never been performed in Iran.

\section{Acknowledgment}

The authors would like to thank all stuttering clients who kindly participated in this research.

\section{Reference}

Amster, B. J., \& Klein, E. R. (2008). Perfectionism in people who stutter: Preliminary findings using a modified cognitive-behavioral treatment approach. Behavioural and Cognitive Psychotherapy, 36(01), $35-40$.

Beck, J. (1995). Cognitive therapy: Basic and beyond. NY: Guilford press.

Blood, G. W. A. (1995). Behavioral-Cognitive Therapy program for adults who stutter: Computers and counseling. Journal of Communication Disorders, 28(2), 165-180.

Bloodstein, O., \& Bernstein Rantner, N. (2008). A handbook on stuttering, $6^{\text {th }}$ ed. Clifton park, NY: Thomson Delmer.

Bothe, A. K. (2003). Evidence-based treatment of stuttering: V. The art of clinical practice and the future of clinical research. Journal of Fluency Disorders, 28(3), 247-258.

Craig, A., Hancock, K., Tran, Y., \& Craig, M. (2003). Anxiety levels in people who stutter: A randomized population study. Journal of Speech, Language, and Hearing Research, 46, 1197-1206.

DiLollo, A., Manning, W. H., \& Neimeyer, R. A. (2003). Cognitive anxiety as a function of speaker role for fluent speakers and persons who stutter. Journal of Fluency Disorders, 28(3), 167-186.

Ezrati-Vinacour, R., Gilboa-Schechtman, E., Anholt, G., Weizman, A., \& Hermesh, H. (2007). Effectiveness of cognitive behaviour group therapy (CBGT) for social phobia (SP) in people who stutter (PWS) with social phobia (SP). In5th world congress of behavioural and cognitive therapies.

Fathi Ashtiyani, A. (2011). Psychological - Personality and Health Evaluation Tests. Tehran. Besat publisher.

Free, M. (2004). Cognitive Group Therapy. Ahoughalandari R. Welfare Organization of Lorestan.

Guitar, B. (2006). Stuttering and integrated approach to its nature and treatment. 3rd Edi, Lippincott Williams \& Wilkins.

Ham, R.(1986). Technisc for Stuttering Therapy. Prentice-Hall, Englewood Cliffs, N.J.

Hawton, K. E., Salkovskis, P. M., Kirk, J. E., \& Clark, D. M. (1989). Cognitive behaviour therapy for psychiatric problems: A practical guide. Oxford University Press.

Holit, R. (1985). Stuttering Therapy.

Menzies, R. G., O'Brian, S., Onslow, M., Packman, A., St Clare, T., \& Block, S. (2008). An experimental clinical trial of a cognitive-behavior therapy package for chronic stuttering. Journal of Speech, Language and Hearing Research,51(6), 1451.

Onslow, M., Costa, L., Andrews, C., Harrison, E., \& Packman, A. (1996). Speech outcomes of a prolonged-speech treatment for stuttering. Journal of Speech, Language and Hearing Research, 39(4), 734-739.

Packman A, \& Kuhn L. (2009). Looking at stuttering through the lens of complexity. International Journal of Speech-Language Pathology, 11,77-82

Reddy, R, \& Sharma, M.P. (2010). Cognitive Behavior therapy for stuttering, Indian. Psychomedica, 32, 49-53.

Shafiei, B, \& Mehralian, Z. (2003).Non fluency disorder in children. Esfahan. Esfahan Medical Sciences university publishing.

Tahmasebi Garmatani, N. (2011). Determination of the Reliability \& validity of the Stuttering Severity Instrument-Fourth Edition. Master thesis of Speech therapy. 